\title{
Methodological Reflections on the Use of Systematic Reviews in Early Childhood Research (Manuscript ID JECR-16-0090)
}

\begin{abstract}
This paper sets out to look critically at the use of systematic reviews in the cross-disciplinary field of early childhood and international development. Systematic reviews - a specialist methodology involving the secondary analysis of existing knowledge on a particular topic - is prevalently used to address complex questions in social and health related policy, and is an established tradition in the life and health sciences. In education and the social sciences, there is burgeoning interest in systematic methodological approaches, although its usage remains comparatively lagging compared to the medical field. Drawing on an interdisciplinary systematic review of empirical research on early childhood development and peacebuilding in the Asia Pacific region, this paper reflects on the use of the methodology and its potential to inform new conceptual and methodological developments. The paper argues that our knowledge of children and the early years can be significantly advanced by furthering debates on systematic reviews particularly in cross-disciplinary fields, its application, as well as relevance for how evidence is evaluated and applied. This is especially pertinent in a sector driven by increasing calls for more reliable and timely information to influence practice and policy decisionmaking.
\end{abstract}

Keywords: early childhood research, methodology, systematic review, cross-disciplinary, evidencebase

\section{Introduction}

In the early years field, there is a global drive to provide reliable and timely information for policy and practice, in order that "evidence-informed" decisions can be made for the benefit of young children and families (OECD 2012; The World Bank 2011; What Works 2014). To this end, it is commonplace for published papers in early childhood research to include some form of literature review, sometimes known as a "narrative review" in its more traditional form, where authors use a selection of literature to develop an argument around what they regard as salient evidence to address a particular research question or hypothesis. The established scholarship of literature reviews published on a wide range of subjects related to early childhood care and education have contributed to advances in knowledge (Hobbs and Stovall 2015; Hedefalk, Almqvist and Östman 2015; Ang, Stephen, and Brooker 2016). However, while literature reviews or desk-based research are routinely published and valuable in their own rights, there appears to be comparatively less critical debate about the application of systematic reviews as a methodological tool in the field. A seminal anthology cites systematic reviews as a rigorous methodology in early childhood research while acknowledging the need for 'methodological diversification' (521) and to 'preclude discussions about how to more wisely and durably position the emerging field of international early childhood research' (Farrell, Kagan, and Tisdall 2016:532).

To address this gap and spur on debate, this paper draws on the methodology and outcomes of a project on a systematic review of early childhood and peacebuilding in the Asia Pacific region, conducted using a review protocol with an online specialist software, the Evidence for Policy and Practice Information (EPPI)-Reviewer 4 tool. The discussion considers how using a systematic review approach has the potential to inform conceptual and methodological developments; and ways in which a methodology that was developed in the health sciences could be adapted for use in the crossdisciplinary fields of early childhood and international development. The paper argues for the importance of maintaining a transparent auditable trail of the methodological process by addressing questions of how the selected literature is reviewed, assessment of the quality of the material included, and potential bias. The discussion contends that the review of evidence using an ordered 
and systematic protocol has the potential to provide a robust synthesis of knowledge. While recognising its limitations, the review process can also be a useful tool for analysing and evaluating studies. This is particularly relevant in a field such as early childhood that is largely dominated by qualitative and descriptive research, where researchers increasingly adopt qualitative datasets to advance theory, policy, and practice (Saracho 2016). The paper examines what is understood by the term 'systematic review' and its relevance for how evidence is evaluated and applied. In doing so, it urges researchers to engage in further critical debates about the use of systematic reviews to advance the scientific rigour and application of research in the early years field. This is all the more pertinent in a sector that is fuelled by increasing demands for more and better evidence to inform policy, practice and theory.

\section{The origins of systematic reviews}

Systematic reviews is essentially a desk-based methodology which employs a standardised, structured protocol and a conceptual framework to review the relevant literature in a methodical and rigorous manner (Gough, Oliver, and Thomas 2012; Khan, Ter Riet, Glanville, Sowden and Kleijnen 2001). It is based on the premise that the best evidence for social change is derived not from single studies or a particular selection of literature, but from scientific analyses and syntheses of multiple studies on the same topic. The methodology was developed first and foremost in response to growing demands by policy makers and practitioners to have access to the most contemporary research evidence for the purpose of decision-making (Harden \& Thomas 2005). Reviews are commonly known to offer aggregate summaries of available body of research on "what works", when and why to address any given question or social phenomena (Gough, Oliver, and Thomas 2012).

Pioneered in health care, the origins of systematic reviews lie in the life and health sciences, where the secondary analysis of large bodies of knowledge is commonplace to inform clinical practice and health related areas. The first international network of systematic reviewers, the Cochrane Collaboration, comprised a group of researchers with a shared vision ' $[t] 0$ improve health by promoting the production, understanding and use of high quality research evidence by patients, healthcare professionals and those who organize and fund our healthcare services' (Cochrane Collaboration, 2016). The collaboration continues to-date as an independent global network of researchers, academics and other professionals with a shared aim to raise awareness of the importance of evidence-based decisionmaking in health care. The review process itself is defined by a series of structured stages that involves the formulation of the research question(s) and methodology, development of a review protocol and search strategy, application of inclusion and exclusion criteria, development of a conceptual framework, appraisal of the quality and relevance of the material, and synthesis of the findings (Oliver and Sutcliffe 2012). Systematic review techniques can be applied to a broad range of evidence using both statistical and narrative approaches including meta-analyses and qualitative research, while drawing on a variety of study types such as effectiveness studies and impact evaluations. As the next section shows, it is also a methodology increasingly used to inform "evidence-based" policy development and advocacy.

\section{Systematic reviews for "evidence-based" early childhood advocacy}

The last decade has witnessed a growing trend in the employment of systematic reviews to enhance evidence-based policy development and advocacy (Snilstveit B., Oliver S. \& Vojtkova 2012; Lohr 2004). The impetus for "evidence" is widely recognised by researchers in a range of fields including education and the early years, to explore solutions to improve the quality of childcare and education of young children (Saracho 2016; Pring and Thomas 2004; Green, Taylor, Buckley and Hean 2016; Cutspec 2004; Pawson 2002). Systematic reviews in early childhood research has been associated with the "gold standard" randomised contolled trial (RCT) methodology in the thorough way it enables data to be scrutinised and compared (Penn 2015). In the United Kingdom, this emphasis on evidence-based research has contributed to a strong "what works" agenda in the development of 
policy and practice. A series of 'What Works Centres' was created in 2010 in the areas of education and early intervention with a focus on collating and applying the "best evidence" to improve public services (Cabinet Office 2014). A key purpose of the Centres is to support policy decision-making regarding the care and education of young children. Led by the Early Intervention Foundation (EIF) , a key focus is the cost-benefit analyses of early intervention programmes, to address questions of how best to improve developmental outcomes for preschool children.

Arguably, researchers have raised conceptual and methodological concerns about the "what works" agenda as to the type of evidence that constitutes quality and "valid knowledge" (Vandenbroeck, Roets and Roose 2012; Biesta 2007; Pampaka, Williams and Homer 2016; Moss 2015); for example, there are contentions around the dominance of RCTs used to inform 'evidence-based' educational practice (Biesta 2007), and the application of an evidence-based discourse to intervention studies across different contexts, time, place, or scale (Penn 2015; Pawson 2006). Researchers investigating the impact of early interventions argue that while evidence on what works can be helpful in identifying the most beneficial strategy to improving provisions, evidence 'is only one factor that needs to be considered alongside others ...' (Little and Sodha 2012: 13) Moss (2015) strongly urges the need to question 'indeed contest, the positivistic ideal' (89) in the making of evidence-based policy and practice particularly. This is especially pertinent in the field of education where objects of study are situated in a social phenomenon requiring contextualisation and interpretation, and where the positionality and perspective of the researcher and the researched highlight 'the inescapable subjectivity of the social research endeavour' (98). Yet others contend that while 'an unresolved debate' (Pampaka, Williams and Homer 2016:232) persists, the rhetoric of "evidence-informed policy and practice" remains ubiquitous. In early childhood research, there is increasing emphasis on the use of "best evidence" for the purpose of advocacy, to address global challenges related to social inequality that impact aversely on the lives of young children and families. Supranational international organisations such as the United Nations Educational, Scientific and Cultural Organisation (UNESCO), The World Bank, and the Organization for Economic Co-operation and Development (OECD) have contributed to concerted calls for 'evidence-based national policy-making' (UNESCO 2015: pxv) in advocating for better policies, governance and services to improve young children's lives. The OECD (2012) for instance, raises the importance of 'evidence-based policy making' (291) and The World Bank (2011) calls for 'evidence-informed policy making' (The World Bank 2011: 6) to build a 'highquality knowledge base on education reform' (6).

Notably, the work of the International Initiative for Impact Evaluation (3ie), funded by the UK's Department for International Development, the Australian aid agency AusAID and other international donors, has led the way in building a repository of systematic reviews, impact evaluations and evidence-gaps to inform future research and policy development in developing countries. A series of reviews has been published on a range of related topics including the benefits of early childhood interventions (Nores and Barnett 2010), the impact of daycare programmes on child health, nutrition and development in developing countries (Leroy, Gadsden \& Guijarro 2012), and childhood vaccinations in developing countries (Shea, Andersson, and Henry 2009). It is evident that in the cross-disciplinary field of early childhood and international development, systematic review approaches that identify and evaluate bodies of empirical knowledge including experimental and quasi-experimental studies on the effects of early interventions are increasingly being funded to inform policy development particularly in the developing world (Snilstveit, Oliver \& Vojtkova 2012). As the following study shows, the process of undertaking a systematic review has the potential to offer a valuable yet challenging avenue for advancing a developing area of interdisciplinary research.

\section{The Study: A brief overview}


The study is a systematic review conducted over a year on the cross-disciplinary feld of early years and international development, on the topic of 'early childhood and peacebuilding'. The aim was to identify the conceptual underpinnings and knowledge-gaps to inform a future research agenda for the Asia Pacific region. Three overarching research questions framed the project 1 ) what do we know or do not know about the role of early childhood in peacebuilding? 2) What are the different conceptualisations of early childhood and peace building? and 3) how does the literature inform a future research agenda for the advocacy of early childhood and peacebuilding in the region? The impetus of the research was to explore the conceptual and empirical evidence on the associations between early children and peacebuilding, and the role of early childhood programmes that contribute to the rebuilding of social cohesion in post-conflict societies. Given the cross-disciplinary nature of the topic, the study brought together a vast body of literature from disciplines such as sociology, cultural psychology, philosophy, education, theology, child health, and political science. In doing so, the review served to establish the key paradigms that underpinned central concepts such as 'early childhood', 'peacebuilding', 'fragility' and the multiple ways in which these are conceived in existing literature and theoretical discourses.

\section{Methodology}

The research entailed a protocol-driven methodology which involved the systematic searching and screening of published literature, undertaken alongside an iterative process of data searching, evaluation and analysis. The inquiry was also informed by a conceptual framework and consultations with professionals and practitioners from international non-government organisations. Two research software applications was used - Zotero/ProQuest and the EPPI-Reviewer 4. Both software were used simultaneously during the review process to cross-check the multiple data sources and search categories. Zotero or Proquest is used to aid the database searches, and the EPPI-Reviewer 4 was used as the primary software for managing and screening the data. A systematic search of online databases was conducted using a standardised protocol to capture literature from targeted secondary databases. The review entailed a staged process that involved the formulation of the review questions, development of a review protocol, formulation of inclusion and exclusion criteria, database searches, data extraction, analysis and synthesis of the findings.

A systematic search was carried out using the following online databases: the British Education Index (BEI), ERIC (Education and Resources in Education Index) and the International Bibliography of the Social Sciences (IBSS). A series of search terms or descriptors combined by OR and AND were used Peace building; Peace AND Early childhood d; Peace building AND Children; Peace, Early childhood And Family; Peace, Early childhood AND Community; Conflict Resolution and Early childhood; Peace building AND East Asia; Peace AND [country]. A pre-set review protocol was also developed as a selection criteria for inclusion and exclusion. All items were screened firstly by their title and abstract, and then secondly, by their full article report. The inclusion criteria included those items published in the English language, from 1990 onwards, and included literature which covered the age group 0-12 years, and items relating to a range of education levels - early childhood education (0-7 years), preschool education (0-4), nursery school education (2-5) and infant school education (5-7). Conference abstracts, papers and 'grey literature' (unpublished or informally published studies) were included in the search. The search encompassed the starting date of 1990 onwards. The rationale for the time frame was two-fold. Firstly, the introduction of the United Nations Convention of the Rights of the Child (1989) was a watershed moment for the early childhood and international development sector; thus it was considered likely that literature published from this period onwards was reflective of current policy and/or research developments and therefore relevant to the study. Secondly, the time period was informed by increased interest in the advocacy and scaling up of early childhood and peacebuilding initiatives as highlighted by an initial scoping review. The inclusion criteria included published literature which related to early childhood and peacebuilding comprising theoretical papers as well as empirical research. 


\section{Data analysis and results}

From the review, a list of 122 citations (Appendix 1 ) was identified. A thematic approach was used to analyse the final list of included literature, with the items coded under three emerging themes: conceptual, intervention and advocacy. The data analysis was undertaken in an ongoing, iterative cyclical process, informed by the conceptual framework, research questions, and emerging literature. During the data analysis, the review identified multiple conceptualisations of early childhood and peace building, and these were assessed and synthesized in relation to the review questions and conceptual framework. Three broad categories were used to guide the final data analysis: topic relevance of the literature and how it relates to the research questions, methodological quality of the items especially in regards to research papers, and the type of literature and its function. The data analysis generally adopted a narrative approach by summarizing the key themes and results, and examined the weight of evidence against each theme. The analysis was conducted with the overall aim of synthesising the extant literature around early childhood and peacebuilding. As part of the data analysis and synthesis, a standard coding tool (Appendix 2) was applied in the EPPI- Reviewer 4 to screen and code the data. Examples of inductive codes included 'programme implementation', 'curriculum and pedagogy', 'children's socialisation' and 'children's voices and participation'. From these codes, the overarching themes were formulated. This structured, stepped-process of analysis was undertaken in an iterative process, closely guided by the research questions and conceptual framework.

The results of the review were encapsulated in a review flow diagram (figure 1). A total of 1,126 items were retrieved and imported to the EPPI-Reviewer database, after the removal of duplicates (152 items were identified as 'exact match 100\%'), a final list of 974 items were included for qualitative analysis. All 974 items were screened and irrelevant studies removed, from which 196 items were eventually included based on their title and abstracts. A total of 122 items were coded on their full report and reviewed.

Figure 1 Review Flow Diagram 


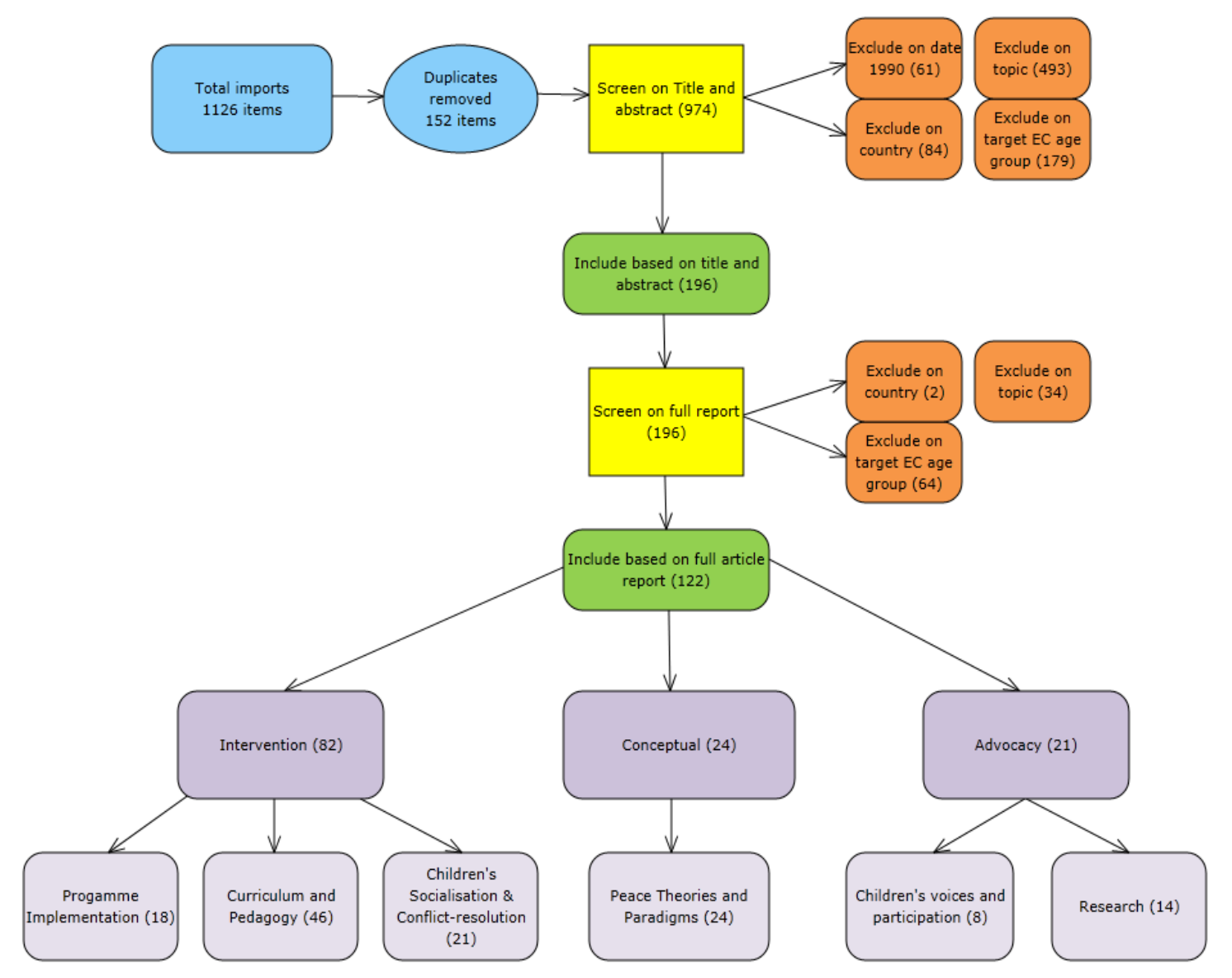

\section{Conceptual framework}

Informed by the analysis and findings, the study was underpinned by a conceptual or theoretical framework depicted in the diagram below (figure 2). The model aimed to visually summarise the findings of the review by encapsulating the complex and extensive literature that have informed conceptualisations of early childhood and peacebuilding. It is based on an ecological paradigm which depicts the powerful influence of different factors and environments which affect children's overall development and well-being (Bronfenbrenner 1979;1995). The framework builds on the research evidence which showed the intrinsic relationships between children, families, communities and the wider society in which they live (Sagi-Schwartz A. 2012 'Children of War and Peace: A Human Development Perspective'; Yale University \& ACEV Partnership (2012) 'Ecology of Peace: Formative Childhoods and Peace Building. A Brief Note.' New Haven, CT and Istanbul, Turkey: Yale-ACEV Partnership).

The model combines concepts spanning academic boundaries which take into account the contextual influences of children's lives in conflict situations. At the center of the model depicts 'the child' amidst its wider environment and positioned within a series of inter-relating and overlapping systems that affect their life experiences. The layer in closest proximity to the child is the family, community and civil society; and the outer layers describe the macro system, the larger cultural, political, historical, and socio-economic conditions that influence the holistic environment in which the child is embedded. In conflict situations, as evidenced by the literature (Ujvari 2005; Schnabel and Tabyshalieva 2013; SagiSchwartz 2012), this is often characterised by deeply ingrained inequalities. When facing adversity, the child therefore stands in the crosscurrents of fractured cultural, political and socio-economic conditions which interact and evolve over time to negatively impact on children's lives and experiences. The theoretical model also shows 'sustainable peace' and 'fragility' as analogous concepts, where the arrows at the bottom-end of the diagram point towards a state of fragility which highlight the adverse 
conditions that children experience in conflict-affected states; in contrast to the arrows at the top-end of the diagram which indicate a movement towards an aspirational ideal - that of sustainable peace. Taken as a whole, the conceptual model illustrates the concept of 'early childhood and peacebuilding' that emerged from the literature reviewed from across and beyond academic disciplines, defined as those social, historical, cultural, political and economic conditions that either enable or hinder the transition from a state of fragility and adversity to the realisation of peace.

\section{Figure 2 Conceptual Framework}

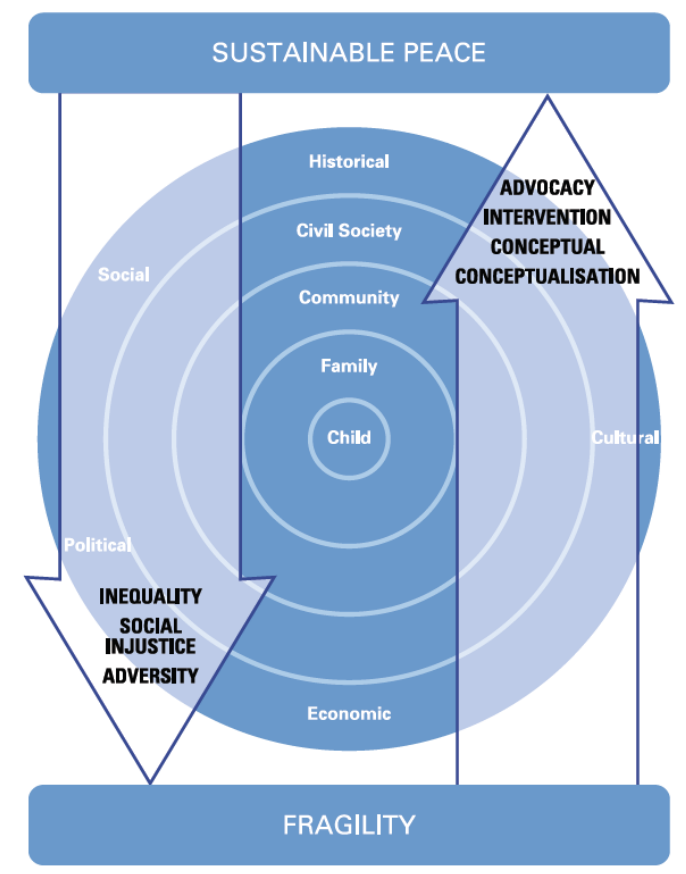

\section{Methodological reflections}

The study presented here shows the methodological process by which a selection of published literature was systematically searched, retrieved and synthesised using a systematic review methodology. The study's aim was to undertake a gap-analysis of existing literature with a view to discovering new areas of inquiry and to inform a research agenda for early childhood and peacebuilding in the Asia Pacific region. To this end, the deployment of a standardised protocoldriven methodology was effective in drawing connections with the existing literature which would otherwise remain obscure and offered the research team an avenue to explore a vast crossdisciplinary field that covered a diverse range of subjects including children, peacebuilding, conflict research, and international development. The electronic software EPPI-Reviewer 4 was instrumental in managing the volume of research that was retrieved across the disciplinary areas. Yet, despite the attention to rigour, there were methodological challenges and dilemmas, which to some extent remained unresolved; not least when adapting the approach to cross-disciplinary fields with contrasting paradigms and research approaches, as well as epistemological, ontological and methodological differences. In an area as context-sensitive as early childhood, the study evoked methodological reflections as well as predicaments in three key areas: 1 . the heterogenity of the literature and selection criteria; 2 . conceptual ambiguities; 3 . risk of bias.

\section{Heterogenity of the literature and selection criteria}

Firstly, a key methodological difficulty encountered at the outset of the study was the heterogeneity of the literature sample and the screening or selection criteria, that is, the process of determining how and which published material should be included in the review. Rather ambitiously, the project 
combined the literature from two substantive distinct topics: early childhood and peacebuilding. Given the cross-disciplinary nature of the study, there was great variability across the literature in theoretical and empirical approaches. The database search captured a diverse set of literature from a range of publication types and documents including books, conference papers, anthologies, journal articles, encyclopaedias, monographs and reference works. Inevitably, given the diversity and variability of the evidence, assessing the relevancy and quality of evidence raised dilemmas, even when a standardised protocol was employed. Some of the studies that were of highly context-specific such as critical discussions of children and peacebuilding in Timor-Leste (Ujvari 2005) and theological research on the Baha'i curriculum for peace education (Gervais 2004) made the selection of literature even more complex as to what constituted "evidence". When reviewing the multidisciplinary literature, a few studies also presented challenges with regards to the evaluation of the research approach and methodology, and underpinning theoretical paradigm, largely because the quality of what is considered acceptable as 'empirical research' varies by discipline. In a cross-disciplinary area such as early childhood and peacebuilding, attempts to apply methodological judgements across academic fields such as theology and geography posed predicaments about what essentially counts as knowledge in the field. As a result, a handful of items, while interesting and valuable in their own rights, had to be omitted because of their methodological limitations and lack of conceptual clarity. The complexities and challenges when pooling and synthesising discipline-specific knowledge are well recognised by researchers even as they espouse the advantages of cross-disciplinary or transdisciplinary research approaches (King, Tucker, Desserud and Shillington 2009). In the context of the study, due to the heterogenity of the field, it was difficult to track down the "grey literature" such as government reports and less widely known research publications as they were either unpublished or published in a native language other than English. This presented a technical limitation which meant that only literature published in the English language was reviewed. As such, it is possible that potentially relevant studies may not have been included and valuable information may be missed.

\section{Conceptual ambiguities}

Secondly, a challenge in the study was the remarkable variations in the underpinning concepts used, and the conceptual ambiguities around terms such as early childhood, fragility and sustainable peace. In any systematic review and indeed desk-based research, the conceptual underpinnings of the given topic area are critical to the inquiry. Depicted in the conceptual model (figure 2), the findings revealed three thematic categories in the conceptualisation of 'early childhood and peacebuilding' - 'conceptual' as part of a wider social justice agenda, 'intervention' as means of conflict mediation and other reconciliation intervention strategies, and 'advocacy' in terms of the promotion of children's rights in peacebuilding. However, these were highly contextualised and used in widely varying combinations. Central to the review were the concepts 'fragility' and 'peace'. Arguably, these concepts are essentially socially, culturally and politically constructed, and as such problematic to define as their meanings are subject to varying usage over time and place. For example, the OECD provided an operational definition of the term 'fragility' as a state of weakened capacity, characterised by a country's inability to carry out basic governance functions with severe challenges in maintaining socially cohesive relations within society (OECD 2013). Yet, the notion of 'fragility' is also a deeply political concept as researchers in the field have noted its multiple dimensions that is understood in different ways in various political, socioeconomic, and cultural discourses. The literature retrieved showed there was limited consensus on what constitutes 'fragility', as all states were considered "fragile" in some respects, and the definition shifted as countries move in and out of fragility. Conversely, the notion of 'peace' is a complex and emotive subject, and arguably elusive to define. The literature showed multiple conceptualisations of 'peace' and 'peacebuilding' (Merav 2001; Klein, Goerrtz and Diehl 2008), and the shifting conceptual links with understandings of childhood and children's role in society. The literature also revealed competing debates around the notion of 'peace' and 'peacebuilding', as constructed by policy makers and scholars (Smith and Carson, 1998; Gervais 2004). 
The diverse vocabulary used across the different fields of literature, where often synonyms were used to mean different things in a range of contexts contributed to the complexity of the review process. Additionally, descriptors that were used inconsistently in the expansive literature to denote the conceptual links between early childhood and peacebuilding such as 'conflict-resolution' and 'childhood resilience' turned out to be more ambiguous than envisaged and was especially challenging when evaluating the relevancy and quality of the literature. The challenge was compounded by the wide range of literature which emerged across different fields and disciplines, reflecting the complexity of the subject area. Frequently used terms such as childhoods, fragility and sustainable peace are value-laden and "travelling" concepts that traverse geopolitical and social contexts, and informed by different fields of researchers with particular world views, philosophies, and theories. Methodologically, this meant that there were implications for the review process as adjustments needed to be made if the wording was changed during the database search or search terms were used in a slightly different way. Hence, although a standardised systematic review protocol was used and consistency maintained in the descriptors included in the database search, conceptual ambiguity remained an ongoing challenge. As a result, the research questions had to be teased out and examined, in part due to the screening process, but mainly to try to provide conclusive answers, even if the answer does no more than to highlight the difficulties in formulating the conceptual difficulties or in relying on particular kinds of evidence. Stewart, Coles and Pullin (2005) aptly describe the researcher's predicament of interpreting complex epistemology while seeking to present a set of coherent findings from very disparate studies as a perennial challenge in any systematic review, 'A balance needs to be struck between a reductionist approach that simplifies the question but may limit both the quantity of information available and the applicability of its conclusions, and a holistic approach in which the question contains so much complexity that no studies have attempted to address it' (277). Inevitably, the overlaps and diversity of terminology used in the study meant the search would not be exhaustive or definitive. Understanding the complexities and indeed conceptual ambiguities of the study therefore presented methodological challenges but was nevertheless pertinent when documenting the relevant research 'evidence' and drawing out the essential elements of the data to create a coherent conceptual framework and narrative. Systematic reviews have traditionally been applied in fields of research where positivist and experimental approaches are dominant. In this case, when applied to a cross-disciplinary study in a comparatively young field of inquiry where descriptive and non-quantifiable studies tend to dominate, there appeared to be less consensus on key conceptualisations and paradigms, giving rise to methodological challenges.

\section{Risk of bias}

Thirdly, the study raised methodological reflections in regards to the issue of risk of bias. As a methodology often associated with scientific rigour, the main aim of any systematic review is to minimise the risk of bias and error associated with single studies and non-systematic reviews, especially when examining a large body of evidence. However, given the extent of heterogeneity of the data sources and conceptual ambiguities, it became apparent during the review that despite the attention to scrutiny and rigor, the review process nonetheless entailed an exercise of judgement when gauging the quality of the evidence and how it might address the research questions. To establish a degree of objectivity, a transparent methodological 'audit trail' was systematically documented as described in the data analysis. Nonetheless, the dilemmas encountered during the review process inevitably posed limitations in that the findings were by no means absolute. The research showed there was no single, universal understanding or theory of "early childhood" and "peacebuilding" as these were essentially value-laden concepts. The study was also conducted within a limited timescale and scope, running the risk that some relevant information has not been captured by the search. As such, it does not purport to offer an exhaustive review of all available literature but rather to map some of the key relevant concepts and literature, in order to understand the knowledge gaps to inform a research agenda for the region. 
The methodological considerations discussed in this paper are pertinent. On one hand, proponents of the approach have argued convincingly of its role as a powerful tool for producing reliable and comprehensive syntheses of the most relevant evidence-base and effectiveness of a given phenomena (Gough, Oliver, and Thomas 2012; Harden and Thomas 2005; Stewart, Van Rooyen, \& de Wet, 2012). Reviews are often regarded as the cornerstone of evidence-based policy making, as a more methodical and therefore 'scientific' approach compared to the practice of literature reviewing in its more traditional form (Anderson and Shemilt 2010). Stewart (2014) argues that 'systematic reviews of research evidence have the potential to 'change the world' by providing accurate comprehensive summaries of knowledge for decision-makers.' (581). It is also perceived as an effective medium for enabling knowledge to be accumulated in a manageable way (Harden and Thomas 2005). On the other hand, researchers have also documented the challenges that arise from systematic reviews particularly in its application to cross-disciplinary research and alternative methodologies (Oliver, Garner, Heywood, Jull, Dickson, Bangpan, Ang, and Fourman 2017). Systematic reviews for instance, are largely perceived to be intervention-based through the synthesis of statistical impact evaluation studies that offer attributable, causal estimates (Tanner, Jeffery, Candland, Tara Lynn, Odden, and Swan 2015); and Dunne (2011) contends that the place of literature reviews in qualitative methodologies can be 'a polemical and divisive issue' (111) given the tensions that arise from the influence of existing, competing frameworks, hypotheses or other theoretical ideas upon the data. Other authors highlighted the difficulties encountered by social scientists and multidisciplinary research teams which include 'inconsistent definitions of social phenomena, differing use of key concepts across research fields and practical problems relating to database compatibility and computer processing power' (Curran, Burchardt, Knapp, McDaid and Li 2007: 289). There are no easy solutions to tackling these challenges but raising these debates is pertinent when considering the implications of systematic reviews and its application.

\section{Conclusion}

This paper has offered some methodological reflections on a systematic review of early childhood and peacebuilding to inform a future research agenda for the Asia Pacific region. While recognising its challenges, the study showed that the principles of systematic reviews has potential for contributing to cross-disciplinary research in the field of early childhood and international development. Governments and supranational organisations internationally are placing greater attention on evidence-informed practice and policy development to improve the lives of young children. In order to meet the growing demands for more "evidence", it is important that early childhood researchers understand the complexities of employing systematic review approaches to address difficult social, global challenges. It is also essential that they carefully consider the most appropriate methods to use, including its strengths and limitations, to be able to identify, appraise, and synthesise the most relevant evidence to enhance the growing knowledge-base of early childhood.

\section{References}

Anderson, R. and Shemilt, I., (2010) The role of economic perspectives and evidence in systematic review. In: I. Shemilt, M. Mugford, L. Vale, K. Marsh, and C. Donaldson, eds. Evidence-based decisions and economics - health care, social welfare, education and criminal justice. 2nd ed. Oxford: Wiley-Blackwell.

Ang L., Stephen C., and Brooker L. (2016) A Review of the Research on Childminding: Understanding Children's Experiences in Home-based Childcare Settings, Early Childhood Education Journal.

Biesta, G. (2007) Why "what works" won't work: Evidence-based practice and the democratic deficit in educational research. Educational Theory 57, no. 1: 1-22. 
Bronfenbrenner U. (1979) The Ecology of Human Development. Cambridge, MA: Harvard University Press.

Bronfenbrenner U. (1995) 'Developmental Ecology through Space and Time. A Future Perspective' in Moen P., Elder G.H., and Luscher K. (Eds.) Examining Lives in Context: Perspectives on the Ecology of Human Development, Washington DC: American Psychological Association.

Cabinet Office (2014) What works? Evidence for decision-makers. London: Cabinet Office https://www.gov.uk/government/uploads/system/uploads/attachment_data/file/378038/What work s evidence for decision makers.pdf

Cochrane Collaboration (2016) Our Vision, Mission and Principles. http://www.cochrane.org/aboutus/our-vision-mission-and-principles.

Cutspec, P.A. (2004) Bridging the research-to-practice gap: Evidence-based education. Centerscope: Evidence-Based Approaches to Early Childhood Development 2(2), pp1-8.

Curran C., Burchardt T., Knapp M., McDaid D. and Li B. (2007) 'Challenges in Multidisciplinary Systematic Reviewing: A Study on Social Exclusion and Mental Health Policy' Social Policy \& Administration 41(3) pp289-312.

Dunne C. (2011) The place of the literature review in grounded theory research, International Journal of Social Research Methodology 14(2), pp111-124.

Early Intervention Foundation, Guidebook (2016) Accessed 12 September 2016

http://guidebook.eif.org.uk/

Farrell A. , Kagan S. L. and Tisdall E.K. (2016) The SAGE Handbook of Early Childhood Research, London: SAGE Publications Ltd.

Gervais M. (2004) 'The Baha'i curriculum for peace education' in Journal of Peace Education, Vol.1 No.2, pp205-224.

Gough D., Oliver S., and Thomas J. (2012) An introduction to systematic reviews, London: Sage Publications.

Harden A. \& Thomas J. (2005) Methodological Issues in Combining Diverse Study Types in Systematic Reviews, International Journal of Social Research

Methodology, 8:3, 257-271

Hobbs M. and Stovall R. (2015) Supporting Mentors of Preservice Early ChildhoodEducation Teachers: A Literature Review, Journal of Early Childhood Teacher Education, 36 pp90-99.

International Initiative for Impact Evaluation (3ie) http://www.3ieimpact.org/

Khan, K.S., Ter Riet, G., Glanville, J., Sowden, A.J., and Kleijnen, J., (2001) Undertaking systematic reviews of research on effectiveness: CRD's guidance for carrying out or commissioning reviews. Research Report. CRD Report ( 4 (2n). NHS Centre for Reviews and Dissemination, York, UK.

King G., Tucker M., Desserud S., Shillington M. (2009) 'The Application of a Transdisciplinary Model for Early Intervention Services' Infants \& Young Children 22(3), pp211-223 
Leroy J.L., Gadsden P. \& Guijarro M. (2012) The impact of daycare programmes on child health, nutrition and development in developing countries: a systematic review, Journal of Development Effectiveness, 4(3) pp.472-496.

Lohr, K. N. (2004) Rating the strength of scientific evidence: Relevance for quality improvement programs. International Journal for Quality in Health Care, 16(1), 9-18.

Little M. and Sodha S. (2012) 'Prevention and Early Intervention in Children's Services' Dartington: Social Science Research Unit https://www.nesta.org.uk/sites/default/files/prevention and early intervention.pdf

Maria Hedefalk, Jonas Almqvist \& Leif Östman (2015) Education for sustainable development in early childhood education: a review of the research literature, Environmental Education Research, 21(7), pp975-990.

Moss P. (2015) 'Where am I? Position and perspective in researching Early Childhood Education' in Farrell A., Kagan S., and Tisdall K. (Eds.) The SAGE handbook of early childhood research (pp. 89-102). Los Angeles/London/New Delhi/Singapore/Washington DC: SAGE Publications Ltd.

Nores M. and Barnett W.S. (2010) 'Benefits of early childhood interventions across the world: (under) Investing in the very young', Economics of Education Review, 29(2) pp271-282.

Organization for Economic Co-operation and Development (OECD), European Union, UNESCO Institute for Statistics (2015), International Standard Classification of Education (ISCED) 2011 Operational Manual: Guidelines for Classifying National Education Programmes and Related Qualifications, OECD

http://www.uis.unesco.org/Education/Documents/isced-2011-operational-manual.pdf

OECD (2012), Starting Strong III: A Quality Toolbox for Early Childhood Education and Care, OECD Publishing.

http://dx.doi.org/10.1787/9789264123564-en

OECD Organisation for Economic Co-operation and Development (2013) Fragile States. Resource flows and trends in a shifting world.

Oliver S., Garner P., Heywood P., Jull J., Dickson K., Bangpan M., Ang L., and Fourman M. (2017) 'Transdisciplinary working to shape systematic reviews and interpret the findings: a Commentary' in Environmental Evidence [Forthcoming]

Oliver S. and Sutcliffe K. (2012) Describing and analysing studies in Gough D., Oliver S., and Thomas J. (2012) An introduction to systematic reviews, London: Sage Publications.

Pampaka M., Williams J. and Homer M. (2016) Is the educational 'what works' agenda working? Critical methodological developments, International Journal of Research \& Method in Education, 39(3), pp231-236.

Pawson, R. (2002) 'Evidence-based policy: The promise of "realist synthesis' Evaluation 8(3) pp34058.

Pawson R. (2006) Evidence-based policy: A Realist Perspective. London: Sage. 
Penn H. (2015) 'Social and Political Landscapes of Childhood' in Farrell A. , Kagan S. L. and Tisdall E.K. (2016) The SAGE Handbook of Early Childhood Research, London: SAGE Publications Ltd.

Penn H. and Lloyd E. (2007), Richness or Rigor? A Discussion of Systematic Reviews and Evidencebased Policy in Early Childhood, Contemporary Issues in Early Childhood 8(1).

Pring, R. and Thomas, G. (2004) Evidence-based Practice in Education. Maidenhead: Open University Press.

Penn H. and Lloyd E. (2006) Using systematic reviews to investigate research in early childhood, Journal of Early Childhood Research, 4(3) pp311-330.

Stewart, R, Van Rooyen, C \& de Wet, T. (2012). Purity or pragmatism: Reflecting on the use of systematic review methodology in development. Journal of Development Effectiveness 4(3), 430-44.

Stewart R. (2014) Changing the world one systematic review at a time: A new development methodology for making a difference, Development Southern Africa, 31:4, pp581-590.

Stewart G, Coles C.F., Pullin A.S. (2005) Applying evidence-based practice in conservation management: Lessons from the first systematic review and dissemination projects. Biological Conservation 126 (2005) 270-278.

Saracho O.N. (2016) Writing and Publishing Qualitative Studies in Early Childhood Education, Early Childhood Education.

Sagi-Schwartz (2012) 'Children of War and Peace: A Human Development Perspective' in Journal of Conflict Resolution 56(5) pp.933- 951.

Schnabel A. and Tabyshalieva A. (Ed.) (2013) Escaping Victimhood. Children, Youth and Post-Conflict Peacebuilding, New York: UN University Press.

Shea, B., Andersson, N. And Henry, D. (2009) 'Increasing the demand for childhood vaccination in developing countries: a systematic review' BMC International Health and Human Rights, 9 (Suppl 1): S5

Snilstveit B., Oliver S. \& Vojtkova M. (2012) Narrative approaches to systematic review and synthesis of evidence for international development policy and practice, Journal of Development Effectiveness, 4(3), 409-429.

Tanner, Jeffery; Candland, Tara Lynn; Odden, Whitney Swan (2015) Later impacts of early childhood interventions : a systematic review. IEG working paper; no. 2015/3. Washington, D.C.: World Bank Group. http://documents.worldbank.org/curated/en/646221468186256866/Later-impacts-of-earlychildhood-interventions-a-systematic-review

The World Bank (2011) Learning for All Investing in People's Knowledge and Skills 
to Promote Development. World Bank Group Education Strategy 2020, Washington: The World Bank http://siteresources.worldbank.org/EDUCATION/Resources/ESSU/Education_Strategy_4_12_2011.pdf

Ujvari (2005) 'Children's peace education in post-conflict Timor-Leste' in Development Bulletin 68, pp.121-164.

United Nations University (2011) http://ccsl.iccip.net/WorldRiskReport2011.pdf

United Nations Educational, Scientific and Cultural Organisation (UNESCO) (2015), Education for All. Global Monitoring Report http://unesdoc.unesco.org/images/0023/002322/232205e.pdf

Vandenbroeck M., Roets G. and Roose R. (2012) 'Why the evidence based paradigm in early childhood education and care is anything but evident', European Early Childhood Education Research Journal, 20 (4), pp537-552. 


\section{Appendix 1 Full list of citations and included items}

Full list of included items from electronic review

1. Allen Susan F; (2009) A Study of a Violence Prevention Program in Prekindergarten Classrooms. Children \& Schools. 31(3): 177187.

2. Arambewela Nadeeka, Arambewela Rodney (2010) Post-war opportunities for peace in Sri Lanka: an ongoing challenge?. Global change, peace and security. 22(3): 365-375.

3. Arnow Jan (1995) Teaching Peace: How To Raise Children To Live in Harmony--Without Fear, Without Prejudice, Without Violence.. : Berkley Publishing Group, 200 Madison Avenue, New York, NY 10016 (\$12 U.S., \$17 Canadian)..

4. Aronhime Raquel, Bennhold-Samaan Laurette, Coratti Nancy, Lazar Cori, Flaccus Trisha Tumulty; McGinnis Randy J: Scammahorn Emmy, Soderstrom Robert, Storti Craig, Williams Krystal (2010) Building Bridges: A Peace Corps Classroom Guide to CrossCultural Understanding. : Peace Corps. Paul D. Coverdell Peace Corps Headquarters, 1111 20th Street NW, Washington, DC 20526.

5. Ashby Nicole, Neilsen-Hewett Cathrine (2012) Approaches to conflict and conflict resolution in toddler relationships. Journal of Early Childhood Research. 10(2): 145-161.

6. Bagshaw Dale, Porter Elisabeth (2009) Mediation in the Asia-Pacific region: transforming conflicts and building peace. : Routledge.

7. Ballif-Spanvill Bonnie, Clayton Claudia J; Hendrix Suzanne B; (2003) Gender, types of conflict, and individual differences in the use of violent and peaceful strategies among children who have and have not witnessed interparental violence. American journal of orthopsychiatry. 73(2): 141-153.

8. Baraldi Claudio, lervese Vittorio (2010) Dialogic mediation in conflict resolution education. Conflict resolution quarterly. 27(4): 423-445.

9. Batiuk Mary Ellen; Boland James A; Wilcox Norma (2004) Project Trust: Breaking down Barriers between Middle School Children. Adolescence San Diego. 39(155): 531.

10. Benton Jean (2005) Using Action Research to Foster Positive Social Values. : Rowman \& Littlefield Publishing Group, 4501 Forbes Blvd., Suite 200, Lanham, MD 20706.

11. (2005) Best Wishes for a Peaceful Classroom. Childhood Education. 82(1): 36.

12. Bettmann Ellen Hofheimer; Moore Pamela (1994) Conflict resolution programs and social justice. Education and urban society. 27(1): $11-21$

13. Bey Theresa M; Turner Gwendolyn Y; (1996) Making School a Place of Peace.. : Corwin Press, 2455 Teller Road, Thousand Oaks, CA 91320 (clothbound: ISBN-0-8039-6192-8; paperback: ISBN-0-8039-6193-6).

14. Biringen Zeynep, Emde Robert N; Pipp-Siegel Sandra (1997) Dysynchrony, conflict, and resolution: positive contributions to infant development. American journal of orthopsychiatry. 67(1): 4-19.

15. Boardman Susan K; Horowitz Sandra V; Deutsch Morton, Rubin Jeffrey Z; Fisher Ronald J; Kressel Kenneth, Frontera Edward A; Forlenza Samuel, Butler Frances, Fish Linda, Redlener Irwin, Zhang Quanwu, Johnson David W; Johnson Roger T; Donnellon Anne, Kolb Deborah M; Rouhana Nadim N; Kelman Herbert C; Kimmel Paul R; (1994) Constructive conflict management: an answer to critical social problems?. Journal of social issues. 50(1): 1-211.

16. Bopage Lionel (2010) Sri Lanka: is there a way forward for peace and reconciliation?. Global change, peace and security. 22(3): 355-364

17. Boyes-Watson Carolyn (2005) Seeds of change: using peacemaking circles to build a village for every child. Child welfare. LXXXIV(2): 191-208.

18. Brantmeier Edward J: (2003) Peace Pedagogy: Exposing and Integrating Peace Education in Teacher Education... . https://login. elibrary.ioe.ac.uk/login?url=http://search.proquest.com/docview/62229573?accountid=27115

19. Briggs Lee R; (2007) An evaluation of 'process as product' in OTI Sri Lanka: a typology of community-level peacebuilding activities and programming recommendation. Journal of peacebuilding and development. 3(3): 22-34.

20. Broadhead Pat (2009) Conflict resolution and children's behaviour: observing and understanding social and cooperative play in early years educational settings. Early Years. 29(2): 105-118.

21. Bruning Merribeth D; (2000) Positive, Peaceful Interactions between Adults and Young Children. Growing Together: Building a Peaceful Community.. : .

22. Buckalew W M; (1979) Peace Education: Opening the Classroom Door... :

23. (2003) Building a World Fit for Children: The United Nations General Assembly Special Session on Children, 8-10 May, 2002. : United Nations Children's Fund, 3 UN Plaza, H-9F, New York, NY 10017. Tel: 212-326-7513; Fax: 212-303-7985; e-mail: pubdoc@unicef.org; Web site: http://www.unicef.org. For full text: http://www.unicef.org/pubsgen/build-wffc/build-wffcen.pdf. https://login elibrary.ioe ac.uk/login?url=http://search proquest.com/docview/62231104?accountid=27115 http:// sfxhosted.exlibrisgroup.com/loe?url_ver=Z39.88-2004\&rft_val_fmt=info:ofi/fmt:kev:mtx:journal\&genre=unknown \&sid=P sfxhosted.exlibrisgroup.com/loe?url_ver=Z39.88-2004\&rft_val_fmt=info:ofi/fmt:kev:mtx:journal\&genre $=$ unknown\&sid=P
roQ:ProQ\%3Aericshell\&atitle $=$ Building $+a+$ World +Fit+for+Children $\% 3 A+T h e+$ United +Nations +General+Assembly+Spe cial+Session+on+Children $\% 2 C+8-10+$ May $\% 2 C+2002$ \&title $=$ \&issn $=\&$ date $=2003-04-01 \&$ volume $=$ \&issue $=\&$ spage $=31 \& a u$ $=\&$ isbn $=\&$ ititle $=\& b$ title $=\&$ rft_id $=$ info:eric/ED475974 
24. (2002) Building Bridges: A Peace Corps Classroom Guide to Cross-Cultural Understanding... Peace Corps Worldwise Schools, 1990 K Street, NW, Suite 9500, Washington, DC 20526. Tel: 800-424-8580, ext. 1450 (Toll Free); Fax: 202-692-1421; e-mail: wwsinfo@peacecorps.gov; Web site: http://www.peacecorps.gov/wws/.

25. Campbell Sheralyn, Castelino Tracy, Coady Margaret, Lawrence Heather, MacNaughton Glenda, Rolfe Sharne, Smith Kylie, Totta Jeni (2002) Our Part in Peace.. : Publications Section, Australian Early Childhood Association. P.O. Box 105, Watson, ACT 2602 Australia (\$12.52 Australian). Tel: 02-6241-6900; Fax: 02-6241-5547; e-mail: publishing@aeca.org.au; Web site: http://www. aeca.org.au.

26. Carlsson-Paige Nancy, Levin Diane E; (1992) Making Peace in Violent Times: A Constructivist Approach to Conflict Resolution. Young Children. 48(1): 4-13.

27. Carlsson-Paige Nancy, Levin Diane E; (1992) When Push Comes to Shove--Reconsidering Children's Conflicts: Beginnings.. Child Care Information Exchange. (84): 34-37

28. Carlsson-Paige Nancy, Levin Diane E; (1992) Moving Children from Time-Out to Win/Win: Beginnings.. Child Care Information Exchange. (84): 38-42.

29. Carter Margie (1992) Disciplinarians or Transformers? Training Teachers for Conflict Resolution: Beginnings.. Child Care Information Exchange. (84): 46-47.

30. Chase Robbie, Doney Anna, Sivaygan S, Ariyaratne V, Satkunanayagam P, Swaminathan A (1999) Mental health initiatives as peace initiatives in Sri Lankan school children affected by armed conflict. Medicine, conflict and survival. 15(4): $379-393$

31. Chaux Enrique (2007) Aulas en paz: a multicomponent program for the promotion of peaceful relationships and citizenship competencies. Conflict resolution quarterly. 25(1): 79-86.

32. Church Ellen Booth; (2005) Building Language Through Conflict Resolution: Discussing Problems Enriches Language While Leading to Solutions. Early Childhood Today. 20(3): 48.

33. Clark Margaret M; Tucker Stanley (2010) Early Childhoods in a Changing World. : Trentham Books Ltd. Westview House 734 London Road, Oakhill, Stoke-on-Trent, Staffordshire, ST4 5NP, UK. Tel: +44-1782-745567; Tel: +44-1782-844699; Fax: +44 1782-745553; e-mail: tb@trentham-books.co.uk; Web site: http://www.trentham-books.co.uk/.

34. Comstock Margaret E; (1974) Building Blocks for Peace: "Love is a Thing to Be Learned".. : Jane Addams Peace Association, 1213 Race St., Philadelphia, Pa. 19107 (\$1.50; \$1.00 each for ten or more copies).

35. Cook Daniel Thomas; Wall John (2011) Children and armed conflict: cross-disciplinary investigations. : Palgrave Macmillan.

36. Cooper Renatta, Jones Elizabeth (2005) Enjoying Diversity. Exchange: The Early Childhood Leaders' Magazine Since 1978. (165): 6-8

37. Cragg Lucy, Nation Kate (2009) Shifting development in mid-childhood: the influence of between-task interference Developmental psychology. 45(5): 1465-1479

38. Crosser Sandra (1992) Managing the Early Childhood Classroom.. Young Children. 47(2): 23-29.

39. Davies-Gibson Miriam R; (1994) Storytelling in the Multicultural Classroom: A Study in Community Building.. :

40. DeJong William (1993) Building the Peace: The Resolving Conflict Creatively Program (RCCP).. : . https://login.elibrary.ioe.ac.uk/ login?url=http://search. proquest.com/docview/62698940?accountid=27115

41. Deng Liang-yu F; (2012) "Parenting about peace": exploring Taiwanese parents' and children's perceptions in a shared political and sociocultural context. Family relations. 61(1): 115-128.

42. Deutsch Morton (1993) Educating for a peaceful world. American psychologist. 48(5): 510-517.

43. Drew Naomi (1995) Learning the Skills of Peacemaking: A K-6 Activity Guide on Resolving Conflict, Communicating, Cooperating Revised and Expanded.. : Jalmar Press, Skypark Business Center, 2675 Skypark Drive, Suite 204, Torrance, CA 90505-5330 (\$24.95).

44. Edwards Carolyn (1992) Creating Safe Places for Conflict Resolution to Happen: Beginnings.. Child Care Information Exchange. (84): 43-45.

45. Eksteen Rodney, Bulbulia Abdulsamed, Niekerk Ashley van; Ismail Ghouwa, Lekoba Royal (2012) Ukuphepha: a multi-level community engagement model for the promotion of safety, peace and health. Journal of psychology in Africa. 22(4): 501-510.

46. Ellis Lindsay (2013) Law and Order in the Classroom: Reconsidering "A Course on Citizenship," 1914. Journal of Peace Education. 10(1): $21-35$

47. Evans Betsy (2002) You Can't Come to My Birthday Party! Conflict Resolution with Young Children.. : High/Scope Press, High/ Scope Educational Research Foundation, 600 North River Street, Ypsilanti, MI 48198-2898 (\$34.95). Tel: 800-40-PRESS (Toll Free); Fax: 800-442-4FAX (Toll Free); e-mail: press@highscope.org; Web site: http://www.highscope.org..

48. Evans Rosalind (2008) The Two Faces of Empowerment in Conflict. Research in Comparative and International Education. 3(1): 50-64

49. Farini Federico (2012) Analysing trust building in educational activities. International Journal of Educational Research. 53: 240250.

50. Farish Jane M; (1995) When Disaster Strikes: Helping Young Children Cope.. : National Association for the Education of Young Children, 1509 16th Street, N.W., Washington, DC 20036-1426 (Order NAEYC No. 533, \$0.50 each; 100 copies, \$10). 
51. Field Harriet (1996) A Wholistic Approach to Conflict Resolution.. : .

52. Field Sarah M; (2013) UN security council resolutions concerning children affected by armed conflict: in whose 'best interest'? International journal of children's rights. 21(1): 127-161.

53. Flannery Daniel J; (2003) Initial Behavior Outcomes for the PeaceBuilders Universal School-Based Violence Prevention Program.. Developmental Psychology. 39(2): 292-308.

54. Gartrell Dan (2010) Beyond Rules to Guidelines. Exchange: The Early Childhood Leaders' Magazine Since 1978. (194): $52-56$.

55. Gervais Marie (2004) The Baha'i Curriculum for Peace Education. Journal of Peace Education. 1(2): 205-224.

56. (2006) Guidebook for Planning Education in Emergencies and Reconstruction. : International Institute for Educational Planning (IIEP) UNESCO. 7-9 rue Eugene-Delacroix, 75116 Paris, France. Tel: +33-45-03-77-00; Fax: +33-40-72-83-66; e-mail: info@iiep. unesco.org; Web site: http://www.unesco.org/iiep.

57. Gustafsson Lars, Barnett Lynn, Lindberg Tor, Levin Lilian, Santa Barbara, Joanna, Woodside Donald, Benner David G; Miller Thomas, Masri Mustafa el; Allodi Frederico, Qouta Samir, Chase Robbie, Doney Anna, Sivaygan S, Ariyaratne V, Satkunanayagam P, Swaminathan A, Spouse Lynn, Piachaud Jack, Summerfield Derek, James Elisabeth (1999) Children and conflict: rights and realities. Medicine, conflict and survival. 15(4): 313-422.

58. Harris lan M; (2000) Peace-Building Responses to School Violence.. NASSP Bulletin. 84(614): 5-24.

59. Haskins Cathleen (2008) Power Picture Books: Tools for Teaching Peace. Montessori Life: A Publication of the American Montessori Society. 20(4): 32-37.

60. Hinitz Blythe (1995) Educating Young Children for Peace... . https://login.elibrary.ioe.ac.uk/login?url=http://search.proquest.com/ docview/62646483?accountid=27115 http://sfxhosted.exlibrisgroup.com/loe?url_ver=Z39.88-2004\&rft_val_fmt=info:ofi/fmt: kev:mtx:journal\&genre=article\&sid =ProQ:ProQ\%3Aericshell\&atitle=Educating +Young +Children + for + Peace. \& title $=E R S+S p$ ectrum\&issn $=07407874 \&$ date $=1995-01-01 \&$ volume $=13 \&$ issue $=4 \&$ spage $=22 \&$ au $=$ Hinitz $\% 2 C+$ Blythe \&isbn $=\& j$ title $=E R S+$ Spectrum\&btitle=\&rft_id =info:eric/EJ517760

61. Hoffman Dorothy (1991) A Child's Right: A Safe and Secure World. The United Nations Convention on the Rights of the Child. Educating for Peace Project.. : United Nations Association-USA, 485 Fifth Avenue, New York, NY 10017-6104 (\$14.95)..

62. Holden Leah (1993) Quilting Integration: A Technical Assistance Guide on Integrated Early Childhood Programs. The Early Integration Training Project.. : NCHRTM-Special Education, Oklahoma State University, 816 West 6th St., Stillwater, OK 740780435 (\$11.25, including postage and handling)..

63. Horio Teruhisa (2006) A View of Children in a Global Age: Concerning the Convention of Children's Rights. Educational Studies in Japan: International Yearbook. (1): 91-99.

64. Hunter Tiffany J; (2008) Creating a Culture of Peace in the Elementary Classroom. Education Digest: Essential Readings Condensed for Quick Review. 74(1): 54-58.

65. Ide Kanako (2007) A Symbol of Peace and Peace Education: The Genbaku Dome in Hiroshima. Journal of Aesthetic Education. 41(4): $12-23$.

66. Ishaq Ashfaq (2004) Peace through Art and Sport. School Arts: The Art Education Magazine for Teachers. 104(3): 41.

67. Jenkins Sandy, Ritblatt Shulamit, McDonald Jeffrey S; (2008) Conflict resolution among early childhood educators. Conflict resolution quarterly. 25(4): 429-450

68. Johnson Celia E; Wan Guofang, Templeton Rosalyn Anstine; Graham Lesley P; Sattler Joan L; (2000) "Booking It" to Peace: Bibliotherapy Guidelines for Teachers.. :

69. Johnson David W; Johnson Roger T; (2005) Essential Components of Peace Education. Theory Into Practice. 44(4): $280-292$.

70. Kim Hyun-Sook (2012) Multicultural Religious Education in a Trinitarian Perspective. Religious Education. 107(3): $247-261$.

71. Kirkwood-Tucker Toni Fuss; (2004) Empowering Teachers to Create a More Peaceful World through Global Education: Simulating the United Nations. Theory and Research in Social Education. 32(1): 56-74.

72. Kleinfeld Margo (2009) The political utility of the nonpolitical child in Sri Lanka's armed conflict. Annals of the Association of American Geographers. 99(5): 874-883.

73. Kreidler William J; (1990) Elementary Perspectives 1: Teaching Concepts of Peace and Conflict.. : Educators for Social Responsibility, 23 Garden Street, Cambridge, MA $02138 .$.

74. Kreidler William J; Furlong Lisa (1995) Adventures in Peacemaking: A Conflict Resolution Activity Guide for School-Age Programs.. : Educators for Social Responsibility, 23 Garden Street, Cambridge, MA 02138.

75. Kreidler William J; Whittall Sandy Tsubokawa; (1999) Early Childhood Adventures in Peacemaking: A Conflict Resolution Activity Guide for Early Childhood Educators. Second Edition.. : Educators for Social Responsibility, 23 Garden Street, Cambridge, MA 02138; Tel: 800-370-2515 (Toll-Free); Tel: 617-492-1764; Web site: http://www.esrnational.org (\$24.95)..

76. Labas Linda, Kendrick Martie, Bilodeau Colette (1999) Building a Foundation for Cooperative Behavior: A LEARNS Early Childhood Monograph. Creating Inclusive Early Care Communities.. : Center for Community Inclusion, Maine's University Affiliated Program, 5717 Corbett Hall, University of Maine, Orono, ME 04469-5717. Tel: 207-581-1084 (voice); Tel: 207-5813328 (TTY); Fax: 207-581-1263; Web site: .

77. Lantieri Linda (2008) Building Inner Resilience. Reclaiming Children and Youth. 17(2): 43-46.

78. (1999) Learning Skills of Peace through Every Day Conflicts: Practical Activities and Resources for Families, Teachers and Other Caregivers. [Loose-Leaf Pages and Pack of Cards].. : . 
79. Levin Diane E: (1994) Teaching Young Children in Violent Times: Building a Peaceable Classroom. A Preschool-Grade 3 Violence Prevention and Conflict Resolution Guide.. : Sales Manager, Educators for Social Responsibility, 23 Garden Street, Cambridge, MA 02138 (paperback--ISBN-0-86571-316-2, \$16.95; $10 \%$ discount to ESR members, add $10 \%$ of total for shipping and handling in U.S. and Canada ( $\$ 2.50$ minimum); add $20 \%$ of total outside U.S. and Canada ( $\$ 4.50$ minimum) discount on quantity orders of $5-49$ copies is $10 \% ; 50$ plus copies is 15\%; New Society Publishers, 4527 Springfield Ave., Philadelphia, PA 19143 (hardback-ISBN-0-86571-315-4, \$44.95).

80. Lubelska Anna (2012) Peaceful schools. International Journal of Children's Spirituality. 17(2): 187-191.

81. MacMullin Colin (2006) Lessons learned investigating the well-being of children affected by armed conflict. In: The challenge of conflict: international law responds. : Martinus Nijhoff, pages

82. Mashford-Scott Angela, Church Amelia (2011) Promoting children's agency in early childhood education. Novitas - Research on Youth and Language (ROYAL). 5(1): 15-38.

83. McMullin Jaremey (2011) Reintegrating young combatants: do child-centred approaches leave children-and adults-behind? Third World quarterly. 32(4): 743-764.

84. Miller Vachel, Ramos Alessandra Mucci; (1999) Transformative Teacher Education for a Culture of Peace.. : . https://login elibrary.ioe.ac.uk/login?url=http://search.proquest.com/docview/62379977?accountid=27115

85. Miller Vachel W; Affolter Friedrich W; (2002) Helping Children Outgrow War. SD Technical Paper.. : Africa Bureau Information Center, 1331 Pennsylvania Avenue, NW, Suite 1425, Washington, DC 20004-1703. E-mail: abic@cdie.org. For full text: http:// www.usaid.gov/regions/afr/pubs. For full text: http://www.ginie.org/children.

86. Miller Suzanne (2005) Building a Peaceful and Just World--Beginning with the Children. Childhood Education. 82(1): 14.

87. (2010) Minimum Standards for Education: Preparedness, Response, Recovery. : Inter-Agency Network for Education in Emergencies. 122 East 42nd Street 14th Floor, New York, NY 10168.. https://login.elibrary.ioe.ac.uk/login?url=http://search. proquest.com/docview/1140136672?accountid $=27115$

88. Montjourides Patrick (2013) Education Data in Conflict-Affected Countries: The Fifth Failure?. Prospects: Quarterly Review of Comparative Education. 43(1): 85-105

89. Montjourides Patrick (2013) Education data in conflict-affected countries: the fifth failure?. Prospects43.1 (Mar 2013):. : 85-105

90. Munter Judith, McKinley Lyn, Sarabia Kristine (2012) Classroom of Hope: The Voice of One Courageous Teacher on the US Mexico Border. Journal of Peace Education. 9(1): 49-64.

91. Murtagh Teresa, O'Sullivan Jean (1998) The Quiet Peacemakers. A Tribute to Teachers.. : UNESCO, Global Action Programme on Education for All, 7 Place de Fontenoy, 75352 Paris 07 SP, France; Tel: (33-1) 456821 27: Fax: (33-1) 456856 24; E-mail: t.murtagh@unesco.org; Web site: http://www.education.unesco.org. https://login.elibrary.ioe.ac.uk/login?url=http://search. proquest.com/docview/62502489?accountid $=27115$

92. Muttha Shantilal (2012) Empowering children for social transformation. Journal of sociology and social anthropology. 3(2): 103118.

93. n , a (2005) Ten Steps for Peace Education. : Alliance for Childhood, PO Box 444, College Park, MD 20741. Tel. and.

94. n , a (2005) Teaching Peace in Fearful Times. : Alliance for Childhood, PO 444, College Park, MD 20741. Tel and.

95. Nurkse Dennis, Castelle Kay (1990) In the Spirit of Peace: A Global Introduction to Children's Rights.. : Defense for Children International-USA, 210 Forsyth Street, New York, NY 10002 (\$7.95, plus \$2.00 shipping)..

96. Parker Sara, Standing Kay, Pant Bijan (2013) Caught in the cross fire: children's right to education during conflict - the case of Nepal 1996-2006. Children and society. 27(5): 372-384

97. Payne Lauren Murphy; Rohling Claudia (1997) We Can Get Along: A Child's Book of Choices [and] Leader's Guide.. : Free Spirit Publishing, Inc., 400 First Avenue North, Suite 616, Minneapolis, MN 55401; phone: 612-338-2068; fax: 612-337-5050 (children's book, \$9.95; leader's guide, \$14.95).

98. Sagi-Schwartz Abraham (2012) Children of war and peace: a human development perspective. Journal of conflict resolution 56(5): 933-951.

99. Salomon Gavriel, Cairns Ed (2009) Handbook on Peace Education. : Psychology Press, Taylor \& Francis Group. 7625 Empire Drive, Florence, KY 41042.

100. Schmidt Fran (1993) Peacemaking Skills for Little Kids. Second Edition. Revised.. : Peace Education Foundation, , 2627 Biscayne Blvd., Miami, FL 33137 (\$19.95, plus \$2 shipping and handling)..

101. Seban Demet (2011) Teaching Peace through Picture Books in a Third-Grade Classroom. Intercultural Education. 22(1): 115-120

102. Segal Marilyn, Adcock Don (1993) Play Together, Grow Together: A Cooperative Curriculum for Teachers of Young Children. Early Childhood Curriculum. Revised and Expanded.. : The Family Center of Nova Southeastern University, Gryphon House, , P.O. Box 207, Beltsville, MD 20704-0207 (\$12.95).

103. Seldin Tim (1999) Building Peace Within Our Adult Community.. Montessori Life. 11(1): 45-47.

104. Singer Elly, Hoogdalem Anne-Greth van; Haan Dorian de; Bekkema Nienke (2012) Day care experiences and the development of conflict strategies in young children. Early Child Development and Care. 182(12): 1661-1672.

105. Slater Marsha, Allsman Ava, Savage Ron, Havens Lani, Blohm Judee, Raftery Kate (2002) Roles of the Volunteer in Development: Toolkits for Building Capacity... : 
106. Standing Kay, Parker Sara (2011) The effect of the 'people's war' on schooling in Nepal, 1996-2006. Education, citizenship and social justice. 6(2): 181-195.

107. Stirling Diane (2000) Character Education Connections for School, Home and Community: A Guide for Integrating Character Education. Grades Pre-K through 12. Revised 2002. Third Edition.. : National Professional Resources, 25 South Regent St., Port Chester, NY 10573 (Order \#CECA-WEB, \$39.95)..

108. Stomfay-Stitz Aline M; Hinitz Blythe F; (1996) Integration of peace education into early childhood education programs. International Journal of Early Childhood. 28(2): 29-36.

109. Stroud Marilyn (1993) Reaching the Children: In Celebration of the Rights of the Child.. : .

110. Thapa Ganga, Sharma Jan (2009) From insurgency to democracy: the challenges of peace and democracy-building in Nepal. International political science review. 30(2): 205-219.

111. Thapliyal Sangeeta (2012) India and Nepal treaty of 1950: the continuing discourse. India quarterly. 68(2): 119-133.

112. Thompson Debra S; (1993) The Integration of Young Children's Literature with Multicultural, Nonsexist, and Global Education Goals and Themes... :

113. Toh Swee-Hin, Cawagas Virginia Floresca; (2010) Peace Education, ESD and the Earth Charter: Interconnections and Synergies Journal of Education for Sustainable Development. 4(2): 167-180.

114. Tribe Rachel (2004) A critical review of the evolution of a multi-level community-based children's play activity programme run by the family rehabilitation centre (FRC) throughout Sri Lanka. Journal of refugee studies. 17(1): 114-135.

115. Troop-Gordon Wendy, Asher Steven R; (2005) Modifications in children's goals when encountering obstacles to conflict resolution. Child development. 76(3): 568-582.

116. Ujvari Danielle (2005) Children's peace education in post-conflict Timor-Leste. Development bulletin. 68: 121-124.

117. Vestal Anita, Jones Nancy Aaron; (2004) Peace Building and Conflict Resolution in Preschool Children. Journal of Research in Childhood Education. 19(2): 131.

118. Wallis Joanne (2012) A liberal-local hybrid peace project in action? The increasing engagement between the local and liberal in Timor-Leste. Review of international studies. 38(4): 735-761.

119. Watson Alison M.S; (2004) The child that bombs built. Studies in conflict and terrorism. 27(3): 159-168.

120. Watson Alison M.S; (2008) Can there be a 'kindered' peace?. Ethics and international affairs. 22(1): 35-42.

121. Wulf Christoph (2010) Education as Transcultural Education: A Global Challenge. Educational Studies in Japan: International Yearbook. (5): 33-47

122. Yamashita Hiromi (2006) Global citizenship education and war: the needs of teachers and learners. Educational review. 58(1): 27-39. 


\section{SCREEN ON TITLE AND ABSTRACT}

- Exclude on target EC age group (exclude items that do not pertain to children 0-8 years)

- Exclude on country (exclude items that are not based on East Asia and the Asia Pacific region)

- Exclude on date 1990 (exclude all items before 1990)

- Exclude on topic (the item is on an entirely unrelated topic)

- Include based on title and abstract

\section{SCREEN ON FULL ARTICLE REPORT}

- Exclude on target EC age group (exclude items that do not pertain to children 0-8 years)

- Exclude on topic (the item is on an entirely unrelated topic)

- Include based on full article report

- Exclude on country

\section{CONCEPTUAL}

- Peace Theories and Paradigms

\section{INTERVENTION}

- Progamme Implementation (Literature relating to peace building at a programme level e.g. early intervention initiatives, toolkits, recommended practices etc.)

- Curriculum and Pedagogy (Literature relating to peacebuilding and early years classroom practices, teaching and learning; teacher training; children's learning)

- Children's Socialisation (Items relating to children's socialisation and peer conflict-resolution issues as a way of promoting peace and peaceful relatinoships.Also relating to children's socialisation within the family, community and society.)

\section{ADVOCACY}

- Children's voices and participation (Literature focusing on children's voices and participation as a form of advocacy for peace building)

- Research (Items provide evidence of empirical research on peace building and EC)

\section{NOTES ON CODES}

1. Exclude on target age groups: Young people and conflict; Women in peace politics; Social emotional well-being in Chilean students; college, Universities and peace corps; Youth intervention and peace; Adolescent; Youth violence

2. Exclude on topics: Human rights issues; Women in conflict situations; Military and defence in conflict situations: Adult education and peace values; Abdominal pain and conflict resolution in children; Children mediation in parental separation; Family mediation; Sibling conflict-resolution; Bullying; Domestic violence and peace; Parental conflict; Parental-adolescent conflict resolution; Global war and peace; Co-parenting divorcing couples and keeping peace; Refugee education and peace; Economics and conflict transformation.

3. Exclude on country: War and peace in Afghanistan and Iraq; Africa and literacy; Rwanda genocide; Poverty alleviation and peace promotion in sub-saharan Africa.

4. Conceptual: Conflict resolution; Peace and social justice; Concepts of war and peace;

5. Curriculum and Pedagogy: Planning for peace in the curriculum; Family-community-school partnerships to promote peace; Storytelling and community building 